\title{
Effect of chain length of short-chain fatty acids on their effect on intracranial pressure in rabbits
}

\author{
DORIS A TRAUNER, HEATHER ADAMS \\ From the Departments of Neurosciences and Pediarrics, University of California School of Medicine, \\ La Jolla, California, USA
}

SUMMARY The short-chain fatty acids propionic, butyric, valeric, isovaleric and octanoic produced elevations in intracranial pressure during intravenous infusion in rabbits. Serum concentrations of these compounds are elevated in patients with Reye's syndrome, and may contribute to the intracranial pressure elevations found in these patients.

Reye's syndrome ${ }^{1}$ is a severe metabolic encephalopathy occurring primarily in children. Mortality from this disease is high and it is one of the 10 most common causes of virus-related deaths in childhood. ${ }^{2}$ Although it typically occurs following a virus infection, the aetiology of Reye's syndrome is unknown. Clinical features of the disease include vomiting, coma, hyperventilation, and seizures. ${ }^{3}$ There is biochemical evidence of liver dysfunction, and the characteristic pathological change is diffuse hepatic microvesicular fatty infiltration. Increased intracranial pressure is a frequent complication and may be difficult to control. 4

Elevations in serum concentrations of the shortchain fatty acids propionic, butyric, valeric, isovaleric, ${ }^{5}$ and octanoic $^{6}$ are present in patients with Reye's syndrome, and serum concentrations appear to correlate with the clinical symptoms. ${ }^{7}$ Infusion of sodium octanoate into rabbits produces clinical, biochemical and pathological changes similar to those found in Reye's syndrome, ${ }^{8}$ and thus appears to be an experimental model for the disease. To test the effects of short chain fatty acids on intracranial pressure, the following study was performed.

\section{Materials and methods}

Twenty male $2 \mathrm{~kg}$ New Zealand albino rabbits were anaesthetised with ketamine $50 \mathrm{mg} / \mathrm{kg}$ and pentobarbital

This research was supported by basic research grant No 1-699 from the March of Dimes Birth Defects Foundation, and by the National Reye's Syndrome Foundation of Bryan, Ohio.

Address for reprint requests: DA Trauner, MD, University Hospital H-815, San Diego, California 92103, USA.

Received 25 May 1981 and in revised form 7 August 1981 Accepted 28 November 1981
$30 \mathrm{mg} / \mathrm{kg}$. In each animal, the femoral artery was catheterised for blood pressure recording and the ear vein cannulated for infusion of test substances. A tracheotomy was performed and the animals mechanically ventilated with a Harvard volume respirator. An incision was made over the occiput and a 20 gauge catheter inserted into the cisternal space for intracranial pressure measurements. Needle electrodes were placed in the scalp over anterior and posterior head regions for electroencephalographic (EEG) recordings. Animals were paralysed with pancuronium bromide $1 \mathrm{mg} / \mathrm{hr}$ and allowed to awaken from the anaesthetic as determined by normalisation of blood pressure and a return of the EEG to an awake pattern. Blood pressure, intracranial pressure, EEG and temperature were recorded continuously throughout the experiment on a Beckman 611 8-channel polygraph. Arterial blood gas determinations were performed during the control period and hourly throughout the experimental period. $\mathrm{pH}, \mathrm{pCO}_{2}$, and $\mathrm{pO}_{2}$ were maintained in the physiologic range by adjusting respiratory rate and volume on the mechanical ventilator.

Sodium propionate, butyrate, valerate, isovalerate and octanoate were infused intravenously in separate experiments as an 0.2 molar solution $\mathrm{pH} 7.4$ at a rate of 0.13 $\mathrm{ml} / \mathrm{min}$ continuously for 6 hours or until the animal died. All solutions were water soluble and free of precipitate. In some rabbits isovalerate was infused at an 0.3 molar concentration. Concentrations of the short chain fatty acids used were based on previous experiments in which octanoate at the same concentration produced the above described clinical, biochemical and pathological abnormalities. $^{8}$ Serum propionate concentrations were measured by the method of Ando et al. ${ }^{9}$ Serum octanoate concentrations were quantitated by a gas chromatographic method described previously."

\section{Results}

Intracranial pressure rose during infusion of sodium propionate, butyrate, valerate and octanoate 428 
(table 1). Isovalerate at the same concentration produced no increase in intracranial pressure, but increasing the concentration to $\mathbf{0 . 3}$ molar caused a rise (table 1).

Toxicity of short chain fatty acids, as measured by survival time following onset of infusion, varied directly with increasing chain length, with the shortest chain compound (propionate) resulting in the longest survival, while octanoate infusion led to the shortest survival (table 2). The rapidity of production of increased intracranial pressure varied with chain length as well, with octanoate producing the most rapid changes.

Table 1 Intracranial pressure elevation during short chain fatty acid infusion

\begin{tabular}{|c|c|c|}
\hline Short chain fatty acid* & $\begin{array}{l}\text { Intracranial pressure max }\left(m m H_{z} O\right) \\
\bar{x} \text { t } S E M\end{array}$ & $p$ \\
\hline $\begin{array}{l}\text { Propionate (3)+ } \\
\text { Butyrate (4) } \\
\text { Valerate (4) } \\
\text { (a) Isovalerate (3) } \\
\text { (b) Isovalerate (3) } \\
\text { Octanoate (4) } \\
\text { Control ICP } \bar{x}+\text { SEM }\end{array}$ & $\begin{array}{l}77.5 \pm 18.8 \\
49.4 \pm 2.6 \\
51.3 \pm 7.0 \\
34.2 \pm 11.7 \\
44.2 \pm 5.8 \\
91.8 \pm 26.4 \\
=24.5 \pm 1.8 \mathrm{mmH}_{2} \mathrm{O}\end{array}$ & $\begin{array}{l}0.001 \\
0.001 \\
0.001 \\
\text { NS } \\
0.001 \\
0.001\end{array}$ \\
\hline
\end{tabular}

All infusions used $0.2 \mathrm{M}$ concentration of sodium salt except (b) isovalerate which was $0.3 \mathrm{M}$.

+ Numbers in brackets indicate $n$ for each group.

Table 2 Toxicity of short chain fatty acids

\begin{tabular}{lll}
\hline Short chain fatty acid & $\begin{array}{l}T \text { max intracrunial pressure } \\
(\text { hr) }\end{array}$ & $\begin{array}{l}\text { T survival } \\
(\text { hr) }\end{array}$ \\
\hline Propionate & 7 & 8 \\
Butyrate & 5 & $6 \cdot 5$ \\
Valerate & 4 & $5 \cdot 5$ \\
Isovalerate & 4 & 6 \\
Octanoate & 2 & $2 \cdot 3$ \\
\hline
\end{tabular}

Arterial $\mathrm{pH}, \mathrm{pO}_{2}$, and $\mathrm{pCO}_{2}$ were monitored throughout the experiment, and although there was a trend toward decreased $\mathrm{pO}_{2}$, the changes were not statistically significant (fig). Octanoate concentrations were undetectable in control serum and reached a maximum of $500 \mu \mathrm{M} / \mathrm{l}$ during infusion of octanoate. Serum propionate concentrations rose from control values of $0.43 \mu \mathrm{M} / \mathrm{I}$ to a maximum of $27 \cdot 15 \mu \mathrm{M} / \mathrm{l}$ during propionate infusion.

\section{Discussion}

Numerous metabolic derangements are present in patients with Reye's syndrome. ${ }^{3}$ One of the most intriguing is the elevation in plasma concentrations of the short chain fatty acids. Serum concentrations of these correlate with the clinical symptoms. ${ }^{7}$ Several other diseases which produce coma and
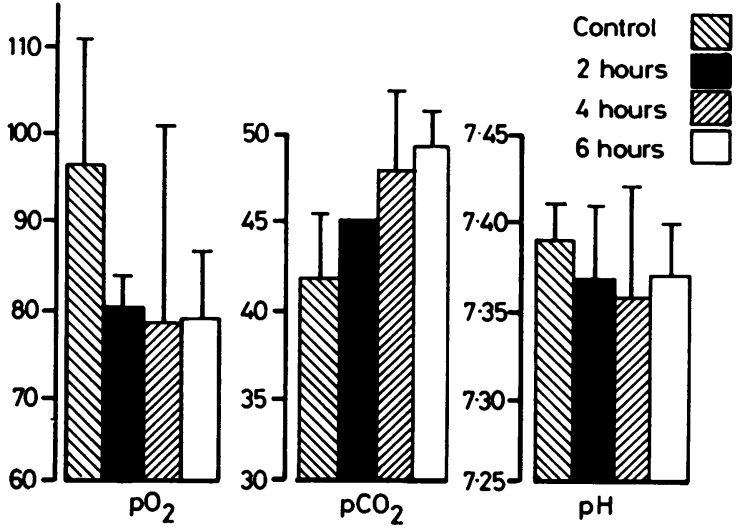

Figure Arterial blood gas determinations during short chain fatty acid infusion $(\bar{x} \pm S E M)$.

hyperventilation share the common feature of shortchain fatty acidaemia. These diseases include Jamaican vomiting sickness, ${ }^{10}$ Udorn encephalopathy, ${ }^{11}$ hepatic encephalopathy, ${ }^{12}$ and isovaleric acidemia. ${ }^{13}$ The fact that several diseases with common clinical features share the same metabolic abnormality suggests a possible role of short chain fatty acids in production of the encephalopathy.

If the short chain fatty acid sodium octanoate is injected into rabbits, it results in coma, hyperventilation, seizures and EEG abnormalities. * Secondary metabolic abnormalities caused by such an injection include hyperammonaemia, lactic acidaemia and mild elevations in serum glutamicoxaloacetic transaminase. ${ }^{8}$ Fatty accumulation in liver and swelling of mitochondria are documented pathological changes. Thus, octanoate infusion appears to produce an experimental model of Reye's syndrome. Injections of other short-chain fatty acids produce milder symptomatology. ${ }^{14}$

The present study demonstrates that the short chain fatty acids propionate, butyrate, valerate and octanoate, and to a lesser extent isovalerate, also produce significant intracranial pressure elevations during continuous intravenous infusion into rabbits. This effect is produced with fatty acid concentrations of the same order of magnitude as those documented in patients with Reye's syndrome. Propionate concentrations rose to $27.15 \mu \mathrm{M} / \mathrm{l}$; mean serum propionate concentrations in patients with Reye's syndrome is $14.89 \mu \mathrm{M} / \mathrm{I}^{7}$ Likewise, octanoate concentrations in patients range from $200-500 \mu \mathrm{M} / \mathrm{I}^{6}$ In rabbits serum concentrations rose to $500 \mu \mathrm{M} / \mathrm{I}$ during octanoate infusion.

Toxicity of the short chain fatty acids increased with increasing chain length. This corroborates other studies demonstrating a relationship between 
chain length and toxicity. Zoborowsky et a/ ${ }^{15}$ found that short chain fatty acids produced mitochondrial swelling in vitro. This effect was seen best with octanoate, the longest chain compound studied. Samson et al ${ }^{16}$ demonstrated that intraperitoneal injections of short chain fatty acids produced coma in rats, and also found that coma was induced more easily as acids of increasing chain length were injected. Isovalerate, the only branched-chain short chain fatty acid studied, produced little change in intracranial pressure at similar concentrations, but did raise the pressure when the concentration was increased. This is of interest for two reasons. First, isovalerate is structurally related to valproic acid, a drug recently added to the list of anticonvulsant medications. One question which arises from the present study is whether valproic acid at high concentrations might produce intracranial pressure elevations and toxic effects by that mechanism. The second point of interest is that children with isovaleric acidaemia, an inborn error of leucine metabolism, have chronic elevations of serum isovaleric acid concentrations yet do not have obvious symptoms of intracranial pressure elevation; but when given a leucine load, these children develop vomiting and lethargy ${ }^{17}$ which might correspond to changes in intracranial pressure.

The mechanism by which the short chain fatty acids produce intracranial pressure elevations has yet to be determined. Experimental studies suggest that they may alter blood-brain barrier permeability. ${ }^{18}$ In addition, they inhibit cerebral $\mathrm{Na}^{+} \mathrm{K}^{+}$ATPase activity 1920 and may thus alter normal neuronal membrane ionic equilibrium. Whatever the mechanism of intracranial pressure elevation, a search for ways to clear short-chain fatty acids from the circulation may result in more effective treatment of the increased intracranial pressure in patients with Reye's syndrome.

\section{References}

' Reye RDK, Morgan G, Baral J. Encephalopathy and fatty degeneration of the viscera - a disease entity in childhood. Lancet 1963;11:749-51.

2 Corey L, Rubin RJ. Reye's syndrome 1974: An epidemiologic assessment. In: Pollack JD, ed. Reye's Syndrome. New York: Grune \& Stratton, 1975:179. 87.

"Huttenlocher PR. Trauner DA. Reye's syndrome. In: Vinken PJ, Bruhn GW, eds. Handbook of Clin Neurol v 29. Amsterdam: North Holland, 1977:33144.
+ Shaywitz BA, Leventhal JM, Kramer MA, Venes JL. Prolonged continuous monitoring of intracranial pressure in severe Reye's syndrome. Pediatrics 1977 ; 59:595-605.

; Trauner DA, Nyhan WL, Sweetman L. Short-chain organic acidemia and Reye's syndrome. Neurology (Minneap) 1975;25:296-8.

- Mamunes P, DeVries CH, Miller CD, David RB. Fatty acid quantitations in Reye's syndrome. In: Pollack JD, ed. Reye's Syndrome. New York: Grune \& Stratton, 1975:245-54.

; Trauner DA, Sweetman L, Holm J, Kulovich S Nyhan WL. Biochemical correlates of illness and recovery in Reye's syndrome. Ann Neurol 1977;2: 238-41.

8 Trauner DA, Huttenlocher PR. Short-chain fatty acidinduced central hyperventilation in rabbits. Neurology (Minneap) 1978;28:940-4.

" Ando T, Rasmussen K, Nyhan WL el al. Propionic acidemia in patients with ketotic hyperglycemia. $J$ Pediatr 1971 ;78:827-33.

11) Tanaka K, Isselbacher KJ, Shih V. Isovaleric and 2 methyl-butyric acidemias induced by hypoglycin $\mathrm{A}$ : Mechanism of Jamaican vomiting sickness. Science 1972;175:69-71.

$"$ Bourgeois C, Olson L, Comer D. Encephalopathy and fatty degeneration of the viscera: A clinicopathologic analysis of forty cases. Am J Clin Pathol 1971:56: 558-71.

12 Muto Y. Chemical study on the relationship of shortchain fatty acids and hepatic encephalopathy. Jap $J$ Gastroenterol 1966;63:19-25.

13 Tanaka D, Budd MA, Efron ML, Isselbacher KJ. Isovaleric acidemia: A new defect of leucine metabolism. Proc Natl Acad Sci USA 1966;56:236-42.

is Trauner DA, Nyhan WL. Sweetman L, Powell HC. Reye's syndrome: Short-chain fatty acid and ammonia studies in experimental animals. In: Pollack JD, ed. Reye's Syndrome. New York: Grune \& Stratton, 1975:415-6.

1: Zoborowski U, Wojtczak L. Induction of swelling of liver mitochondria by fatty acids of various chain length. Biochim Biophys Acta 1963;70:596-8.

1" Samson FE, Dahl DR. A study of the narcotic action of the short-chain fatty acids. J Clin Invest 1956;35: 2191-8.

1: Budd MA, Tanaka K, Holmes LB, Efron ML, Crawford JD, Isselbacher KJ. Isovaleric acidemia: Clinical features of a new genetic defect of leucine metabolism. New Engl J Med 1967;277:321-7.

is Trauner DA, DelaTorre J. Effects of sodium octanoate on blood-brain barrier permeability. Soc Neurosc $i$ (Abs) 1979:3:147.

1" Dahl DR. Short-chain fatty acid inhibition of rat brain $\mathrm{Na}^{+} \mathrm{K}^{*}$ adenosine triphosphatase. $J$ Neurochem $1968 ; 15: 815-21$.

" Trauner DA. Regional cerebral $\mathrm{Na} \cdot \mathrm{K}$ ATPase activity following octanoate administration. Pediatr Res 1980;14:844-5. 